\title{
Connexin 43 reduces susceptibility to sympathetic atrial fibrillation
}

\author{
BEIBEI LUO ${ }^{1 *}$, YIFEI YAN $^{1 *}$, ZHIYU ZENG $^{1}$, ZHENGNAN ZHANG $^{1}$, HAIDE LIU ${ }^{1}$, \\ HAO LIU ${ }^{2}$, JINYI LI ${ }^{2}$, WEIQIANG HUANG ${ }^{1}$, JIANGTAO WU ${ }^{1}$ and YAN HE ${ }^{1}$ \\ Departments of ${ }^{1}$ Geriatric Cardiology and ${ }^{2}$ Cardiology, \\ The First Affiliated Hospital of Guangxi Medical University, Nanning, Guangxi 530000, P.R. China
}

Received January 17, 2017; Accepted April 24, 2018

DOI: $10.3892 / \mathrm{ijmm} .2018 .3648$

\begin{abstract}
Atrial fibrillation (AF) is the most common arrhythmia reported in clinical practice. Connexin $43(\mathrm{Cx} 43)$ is a member of the connexin protein family, which serves important roles in signal transduction in vivo. The aim of the present study was to investigate the role of $\mathrm{Cx} 43$ in the induction and maintenance of atrial fibrillation by using an animal model of sympathomimetic atrial fibrillation. Cx43 was successfully knocked down in the myocardium with gene-specific small interfering (si)RNA via lentiviral infection. A total of $25 \mathrm{dogs}$ were randomly and evenly divided into five groups: $\operatorname{Normal}(\mathrm{N})$, rapid atrial pacing (RAP), isoproterenol (ISO) + RAP, RAP + Cx43 siRNA and ISO + RAP + Cx43 siRNA. The mRNA and protein levels, as well as the distribution of $\mathrm{Cx} 43$ on the cell membrane, were gradually decreased in each group compared with the $\mathrm{N}$ group following treatment $(\mathrm{P}<0.05)$. The induction rate of the atrial effective refractory period was not significantly affected in the RAP and RAP + Cx43 siRNA groups, whereas it was significantly reduced in the ISO + RAP and $\mathrm{ISO}+\mathrm{RAP}+\mathrm{Cx} 43$ siRNA groups compared with the N group $(\mathrm{P}<0.05)$. The induction rate of AF was gradually increased in the RAP + Cx43 siRNA, ISO + RAP and ISO + RAP + Cx43 siRNA groups compared with the $\mathrm{N}$ group $(\mathrm{P}<0.05)$. The expression of nerve growth factor (NGF) and tyrosine hydroxylase $(\mathrm{TH})$ was gradually increased in the ISO + RAP and ISO + RAP + Cx43 siRNA groups compared with their respective controls (RAP and RAP $+\mathrm{Cx} 43$ siRNA groups, respectively). However, no significant difference in the levels of NGF and TH was observed between the RAP, RAP + Cx43 siRNA, ISO + RAP and ISO + RAP + Cx43 siRNA groups. The mitochondrial morphology in each group was notably
\end{abstract}

Correspondence to: Professor Yan He, Department of Geriatric Cardiology, The First Affiliated Hospital of Guangxi Medical University, 6 Shuangyong Road, Nanning, Guangxi 530000, P.R. China E-mail: hyxjwxy@126.com

*Contributed equally

Key words: connexin 43, atrial fibrillation, atrial effective refractory period, small interfering RNA silencing altered compared with the $\mathrm{N}$ group. The mitochondrial reactive oxygen species production and apoptotic index were gradually increased in each group compared with the $\mathrm{N}$ group $(\mathrm{P}<0.05)$. The results of the present study suggest that $\mathrm{Cx} 43$ reduces susceptibility to AF. Downregulation of Cx43 mediates the induction and maintenance of sympathetic AF.

\section{Introduction}

Atrial fibrillation (AF) is the most common cardiac arrhythmia reported in clinical practice (1). There are three predominant mechanisms underlying AF: Electrical remodeling, structural remodeling and autonomic nerve remodeling (2). It is generally recognized that autonomic nerve remodeling serves an important role in the induction and maintenance of atrial tachycardia and AF (3). A previous study demonstrated that myocardial infarction causes sympathetic hyperplasia, which is associated with an increased rate and prolonged duration of AF (4). However, it remains unclear how sympathetic hyperplasia results in AF. It is known that connexins serve an important role in signal transduction in vivo. Connexins mediate a number of small molecules, including adenosine 5'-triphosphate, cyclic adenosine 5'-phosphate, inositol triphosphate and glucose, to pass through the cell membrane (5). In the heart, connexins mediate electrical coupling among cardiac myocytes to form signal channels, allowing for the transmission of electrical waves that are responsible for synchronized contraction among tissues (6). Connexin 43 (Cx43), a member of the connexins family, is most abundantly expressed in the cardiac muscle (7). Cx43 has been demonstrated to serve a role in a number of diseases, including oral squamous cell carcinoma, pancreatic cancer, prostate cancer, acute myeloid leukemia, myocardial edema, vascular restenosis and Parkinson's disease (8-17). Cx43 is primarily a fast, low-resistance pathway that regulates electrical conduction between cardiomyocytes, coordinates mechanical and electrical activities of cardiac muscle and controls the conduction velocity of impulses to ensure that myocardial electromechanical activities are synchronized (18). A previous study revealed that $\mathrm{Cx} 43$ remodeling, which predominantly occurs during oxidative stress, is associated with the induction and maintenance of AF (19).

Clinical data indicate that $\mathrm{Cx} 43$ is dysregulated in patients with AF compared with normal controls (20). In the present 
study, canine models of cardiac Cx43 knockdown and heart perfusion were established. In these models, the excitatory effect of the sympathetic nerve was mimicked without the impact of neurohumor. The possible mechanisms underlying how the sympathetic nerve mediates the induction and maintenance of AF were explored.

\section{Materials and methods}

Materials and animals. A total of 25 hybrid dogs (52\% male and $48 \%$ female; aged 4-5 months; body weight 2-3 kg) from the Guangxi Medical University Laboratory Animal Center (Nanning, Guangxi, China) were housed at $2^{\circ} \mathrm{C}$ in an atmosphere with $40 \%$ humidity, a 12-h light/dark cycle and free access to food and water. They were randomly and evenly divided into five groups: Normal control (N) group, rapid atrial pacing (RAP) group, isoproterenol (ISO) perfusion + RAP, RAP + Cx43 small interfering (si)RNA group and ISO + RAP + Cx43 siRNA. All animal experiments were approved by the Ethics Committee of the First Affiliated Hospital of Guangxi Medical University (Nanning, Guangxi, China). ISO, pentobarbital sodium powder, heparin and modified Tyrode's solution were purchased from Cable Noble (Beijing, China).

Treatments for each group. In group N, dogs were anesthetized with $3 \%$ sodium pentobarbital $(30 \mathrm{mg} / \mathrm{kg})$ by intraperitoneal injection and fixed on the operating table. Sternotomy was performed, the left ventricle of the heart was injected with 8,000 units heparin and the heart was subsequently removed and placed in pre-cooled Tyrode's solution. The remaining blood was squeezed out and then the heart was quickly connected to the isolated heart perfusion apparatus. Cardiac perfusion (50 $\mathrm{ml} / \mathrm{min}$ ) was performed with Tyrode's solution below $37.5^{\circ} \mathrm{C}$. The heart was manually pressed during perfusion to bring the beat rate up to $100 \mathrm{bpm}$. Needle-like electrodes were placed on the atrial appendage and cardiac apex and connected to the electrophysiological instrument and stimulator. An electrocardiogram (ECG) was recorded and the atrial tissue was sampled following continuous perfusion for $\sim 1 \mathrm{~h}$.

In the RAP group, perfusion was performed as above. The heart was stimulated at the frequency of $800 \mathrm{bpm}$ for $30 \mathrm{sec}$ a total of 30 times. In the ISO + RAP group, the heart was perfused with modified Tyrode's solution containing $0.1 \mu \mathrm{mol} / 1$ ISO and the remaining steps were the same as those in the RAP group. For the RAP + Cx43 siRNA group, dogs were anesthetized with $3 \%$ sodium pentobarbital $(30 \mathrm{mg} / \mathrm{kg})$ via intraperitoneal injection and an artificial airway was created through the connection to an auxiliary ventilator. Sternotomy was performed to create a $4-\mathrm{cm}$ incision. The pericardium was opened to cradle the heart. A total of $5 \mathrm{ml}$ solution containing lentivirus (20\% poloxamer 407, 0.5\% trypsin, 6x108 TU lentivirus carrying siRNA against $\mathrm{Cx} 43$, sense: 5'-AAGACT GTGGATCTCCGAAA-3'; anti-sense: 5'-GCTCACTTG CTTGTTTGTTG-3'; Takara Bio, Inc., Otsu, Japan.) was injected into the left and right atria using a camelhair brush to establish a knockdown animal model of $\mathrm{Cx} 43$. The heart was then sutured. A total of 2 million units penicillin were injected intramuscularly following surgery. Heart perfusion was performed 3 weeks later following the same protocol used in the RAP group.
In the ISO + RAP + Cx43 siRNA group, a similar protocol was followed as performed in the RAP + Cx43 siRNA group, except that the heart was perfused with $0.1 \mu \mathrm{mol} / 1 \mathrm{ISO}$.

Evaluation of the efficiency of lentiviral infection. The myocardial samples from group $\mathrm{N}$ and the knockdown group were quickly placed on the sample holder of a freezing microtome, embedded with optimum cutting temperature compound and frozen for $30 \mathrm{~min}$. Subsequently, the samples were cut into sections (5 $\mu \mathrm{m}$ thick). Sections were examined for the intensity of green fluorescence protein (GFP) conjugated to the lentivirus under a fluorescence microscope (magnification, $\mathrm{x} 400$ ) in a dark room. The efficiency of lentiviral infection was assessed according to the intensity of GFP.

Electrophysiological parameters. The electrophysiological parameters were tested once the beats of the isolated heart became steady. The S1S2 stimulation approach was taken to determine the atrial effective refractory period (AERP) (21). S1S2 coupling interval was initiated from the basic cycle with 300-msec length. The proportion of stimulation was 8:1. The step length was decreased by $10 \mathrm{msec}$ with $2 \mathrm{msec}$ of pulse. The power of stimulus was twice that of the diastolic threshold. This was performed until the longest atrium S1S2 interval failed to be within the AERP. The testing was repeated three times and the values were averaged. The induced AF was defined as an irregular atrial electrical activity when the duration was $>2 \sec (21)$. The number of induced AF was recorded for each group, excluding group $\mathrm{N}$.

Immunohistochemical analysis for NGF and TH in the atrial myocardium. The left atrial tissue was rinsed with saline, fixed in $10 \%$ formaldehyde at $4^{\circ} \mathrm{C}$ for $24 \mathrm{~h}$, embedded in paraffin and cut into 5- $\mu \mathrm{m}$ sections. Briefly, the dewaxed sections were incubated with $3 \%$ hydrogen peroxide $\left(\mathrm{H}_{2} \mathrm{O}_{2}\right)$ for $10 \mathrm{~min}$ at room temperature followed by blocking with $5 \%$ bovine serum albumin (SW3015; Beijing Solarbio Science and Technology Co., Beijing, China) at $37^{\circ} \mathrm{C}$ for $1 \mathrm{~h}$. The primary antibodies anti-NGF (bs-0067R-Cy3; BIOSS, Inc., Boston, MA, USA; 1:500) and anti-TH (bs-3463R; Bioss, Inc.; 1:300) were added and incubated at $4{ }^{\circ} \mathrm{C}$ overnight. The next day, the sections were rinsed with PBS and incubated with biotinylated secondary antibodies conjugated with horseradish peroxidase (HRP; PV-6001; OriGene Technologies, Inc., Beijing, China) at $37^{\circ} \mathrm{C}$ for $1 \mathrm{~h}$. The tissue sections were incubated with the Chemicon Liquid DAB Substrate-Chromogen System (PV-6001; OriGene Technologies, Inc.) for $2-3 \mathrm{~min}$ at $37^{\circ} \mathrm{C}$ to visualize the immunoreactive products. The sections were then counterstained with diluted hematoxylin for $15 \mathrm{sec}$ at room temperature, rinsed with alcohol solution for $3 \mathrm{sec}$, dehydrated through a graded alcohol series and then mounted. Stained samples were examined under a light microscope (magnification, x400).

Immunofluorescence staining for Cx43. Atrial sections were prepared and blocked as above. The primary polyclonal rabbit anti-Cx43 antibody (3512; Cell Signaling Technology, Inc., Danvers, MA, USA; 1:50) was added and incubated at $4{ }^{\circ} \mathrm{C}$ overnight. The following day, slides were rinsed with PBS and incubated with fluorescein isothiocyanate-labeled secondary antibody (sc-2012; Santa Cruz Biotechnology, Dallas, TX, 
USA; $1: 100)$ at $37^{\circ} \mathrm{C}$ for $1 \mathrm{~h}$. The sections were then rinsed with PBS, stained with DAPI at $37^{\circ} \mathrm{C}$ for $10 \mathrm{~min}$ and mounted with buffered glycerol. Stained samples were examined under a light microscope (magnification, $\mathrm{x} 400$ ).

Western blot analysis. The atrial tissue was ground in liquid nitrogen and lysed in radioimmunoprecipitation assay buffer containing $100 \mathrm{mg} / \mathrm{l}$ PMSF. Total protein was extracted and the concentration was determined using the bicinchoninic acid method. Total protein $(40 \mu \mathrm{g})$ was separated using $12 \%$ SDS-PAGE and transferred onto a polyvinylidene fluoride membrane. The membrane was blocked with 5\% skim milk at room temperature for $1 \mathrm{~h}$ and incubated with mouse $\mathrm{Cx} 43$ monoclonal antibody (sc-13558; Santa Cruz Biotechnology; 1:1,000) and mouse GAPDH monoclonal antibody (KC-5G4; KangChen Bio-tech, Shanghai, China, $1: 10,000)$ at $4^{\circ} \mathrm{C}$ overnight. The following day, the membrane was incubated with the secondary antibody conjugated with HRP (KC-MM-035; KangChen Bio-tech; 1:10,000) at room temperature for $2 \mathrm{~h}$. The membrane was washed with Tris-buffered saline-Tween 20 three times. Enhanced chemiluminescence (KangChen Bio-tech) was used to develop the film.

Reverse transcription-quantitative polymerase chain reaction (RT-qPCR). RT-qPCR was performed to detect the expression level of Cx43. RNA was extracted from canine atrial tissue and atrial myocytes using TRIzol (Invitrogen; Thermo Fisher Scientific, Inc., Waltham, MA, USA) and treated with DNase I (Promega Corp., Madison, WI, USA). Reverse transcription was performed with $0.5 \mu \mathrm{g}$ of RNA using a Prime Script RT Master Mix reagent kit (RR036A; Takara Bio, Inc.). qPCR was performed using a SYBR Premix Ex Taq kit (638320; Takara Bio, Inc.). $\beta$-actin was used as a housekeeping control. Thermocycling conditions were as follows: $95^{\circ} \mathrm{C}$ for $2 \mathrm{~min}$ followed by 40 cycles of $95^{\circ} \mathrm{C}$ for $15 \mathrm{sec}$ and $60^{\circ} \mathrm{C}$ for $32 \mathrm{sec}$. The following primers were used: $\beta$-actin, forward $5^{\prime}$-TGA GCGCAAGTACTCTGTGT-3' and reverse 5'-AACAGTCCG CCTAGAAGCAT-3'; and Cx43, forward 5'-AAGACTGTG GATCTCCGAAA-3' and reverse 5'-GCTCACTTGCTTGTT TGTTG-3'. The expected sizes of $\beta$-actin and Cx43 were $\sim 140$ and $\sim 150$ bp, respectively. Relative mRNA level was calculated using the $2^{-\Delta \Delta \mathrm{Cq}}$ method (22). The relative expression level of $\mathrm{Cx} 43$ was quantified by using $\beta$-actin as an internal control.

Reactive oxygen species (ROS) measurement with fluorometry. The atrial muscle tissue from each group was collected and quickly cut into pieces $\left(1 \mathrm{~mm}^{3}\right)$ on ice within $1 \mathrm{~h}$. Mitochondria was isolated using a Mitochondria Extraction kit (C3606; Biyuntian, Shanghai, China). Isolated mitochondrial samples were added to microplate wells containing respiration buffer comprising $5 \mathrm{mM}$ pyruvate, $2.5 \mathrm{mM}$ malate, $10 \mu \mathrm{M} \mathrm{H}_{2} \mathrm{DCF} / \mathrm{DA}$ and $5 \mu \mathrm{M}$ HRP. Following incubation for $10 \mathrm{~min}$ at $37^{\circ} \mathrm{C}$, fluorescence was measured at $37^{\circ} \mathrm{C}$ with an excitation wavelength of $485 \mathrm{~nm}$ and emission wavelength of $532 \mathrm{~nm}$. ROS production was determined by subtracting the fluorescence intensity measured in control wells that contained assay buffer without mitochondria according to Korde's method (19).

Transmission electron microscopy (TEM). The atrial tissue was cut into pieces $<1 \mathrm{~mm}^{3}$ and quickly fixed in $2.5 \%$ glutaraldehyde for $2 \mathrm{~h}$ at room temperature and then overnight at $4^{\circ} \mathrm{C}$. The next day, specimens were post-fixed in $1 \%$ buffered osmium tetroxide at $4^{\circ} \mathrm{C}$ for $2 \mathrm{~h}$ and then dehydrated through a graded ethanol series and embedded in epoxy resin. Ultrathin sections $(90 \mathrm{~nm})$, double-stained at room temperature with 5\% uranyl acetate for $15 \mathrm{~min}$ and $2 \%$ lead citrate for $7 \mathrm{~min}$, were examined using an electron microscope (H-800; Hitachi, Tokyo, Japan).

TUNEL assay. The left atrial tissue was fixed with $10 \%$ formalin at $4^{\circ} \mathrm{C}$ for $24 \mathrm{~h}$ and then embedded in paraffin. TUNEL assay was performed using a Roche In Situ Cell Death Detection Kit (Roche Applied Science, Penzberg, Germany). Deparaffinized sections were treated with $3 \%$ hydrogen peroxide in methanol at $37^{\circ} \mathrm{C}$ for $10 \mathrm{~min}$. After adding the equilibration buffer, sections were treated with TdT-enzyme at $37^{\circ} \mathrm{C}$ for $1 \mathrm{~h}$ and then incubated with HRP-conjugated antibodies at $37^{\circ} \mathrm{C}$ for $30 \mathrm{~min}$ (provided in the kit; Roche Applied Science). Then sections were colorized with DAB for 2-3 min at $37^{\circ} \mathrm{C}$ (ZLI-9017; ZSGB-BIO, Beijing, China). Hematoxylin was used for nuclear counter staining at $37^{\circ} \mathrm{C}$ for $5 \mathrm{~min}$. Normal myocardial nuclei were blue-green while apoptotic nuclei of TUNEL-positive cell appeared brown. Finally, the stained sections were examined under a light microscope. Five high-power fields were selected for each slide. The data were expressed as the percentage of TUNEL-positive cells relative to total number of cells counted.

Statistical analysis. The data were expressed as the mean \pm standard deviation. One-way analysis of variance with Tukey-Kramer post hoc test was used to compared groups. SPSS v18.0 (SPSS, Inc., Chicago, IL, USA) was used for data analysis. $\mathrm{P}<0.05$ was considered to indicate a statistically significant difference.

\section{Results}

Evaluation of infection efficiency in the atrial muscle. The lentivirus carrying green fluorescence protein and Cx43 siRNA was injected into the myocardial tissue and the infection efficiency was evaluated by examining the intensity of green florescence protein. At 3 weeks post-infection, a strong green fluorescence signal was observed in the Cx43 knockdown group, but not in the $\mathrm{N}$ group (Fig. 1).

Expression of Cx43 in each group and its knockdown efficiency. In the $\mathrm{N}$ group, $\mathrm{Cx} 43$ protein was expressed and localized in the intercalated disk of the myocardium, predominantly in an end-to-end and strip pattern. A punctate pattern was also observed in a small portion of cells. In the RAP group, Cx43 was mildly expressed and predominantly distributed along the long axis of the myocardium in a side-to-side and strip pattern, with a punctate distribution in a small portion of cells. In the ISO + RAP group, the expression of Cx43 was notably decreased compared with the RAP group and distributed in a punctate pattern. In the RAP + Cx43 siRNA group, the expression of $\mathrm{Cx} 43$, presented in a side-to-side or punctuate pattern, was markedly decreased compared with the ISO + RAP group. In the ISO + RAP + Cx43 siRNA group, Cx43 was distributed in a sporadic pattern (Fig. 2A).

RT-qPCR was then performed to detect the expression of Cx43 mRNA in the atrial muscle. The expression of Cx43 mRNA was decreased in each group compared with the $\mathrm{N}$ group 

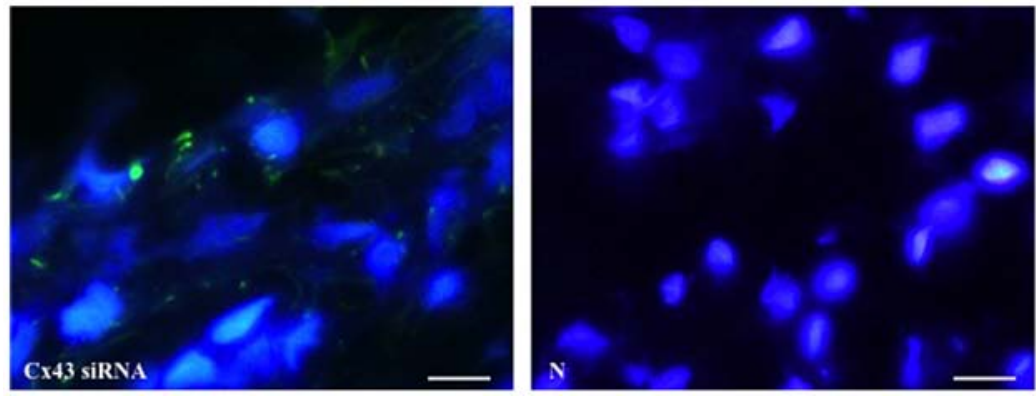

Figure 1. Cx43 knockdown was achieved by infection with Cx43 siRNA. Green fluorescent protein was observed using fluorescence microscopy. Scale bar $=50 \mu \mathrm{m}$. Cx 43 , connexin 43; siRNA, small interfering RNA; N, normal.
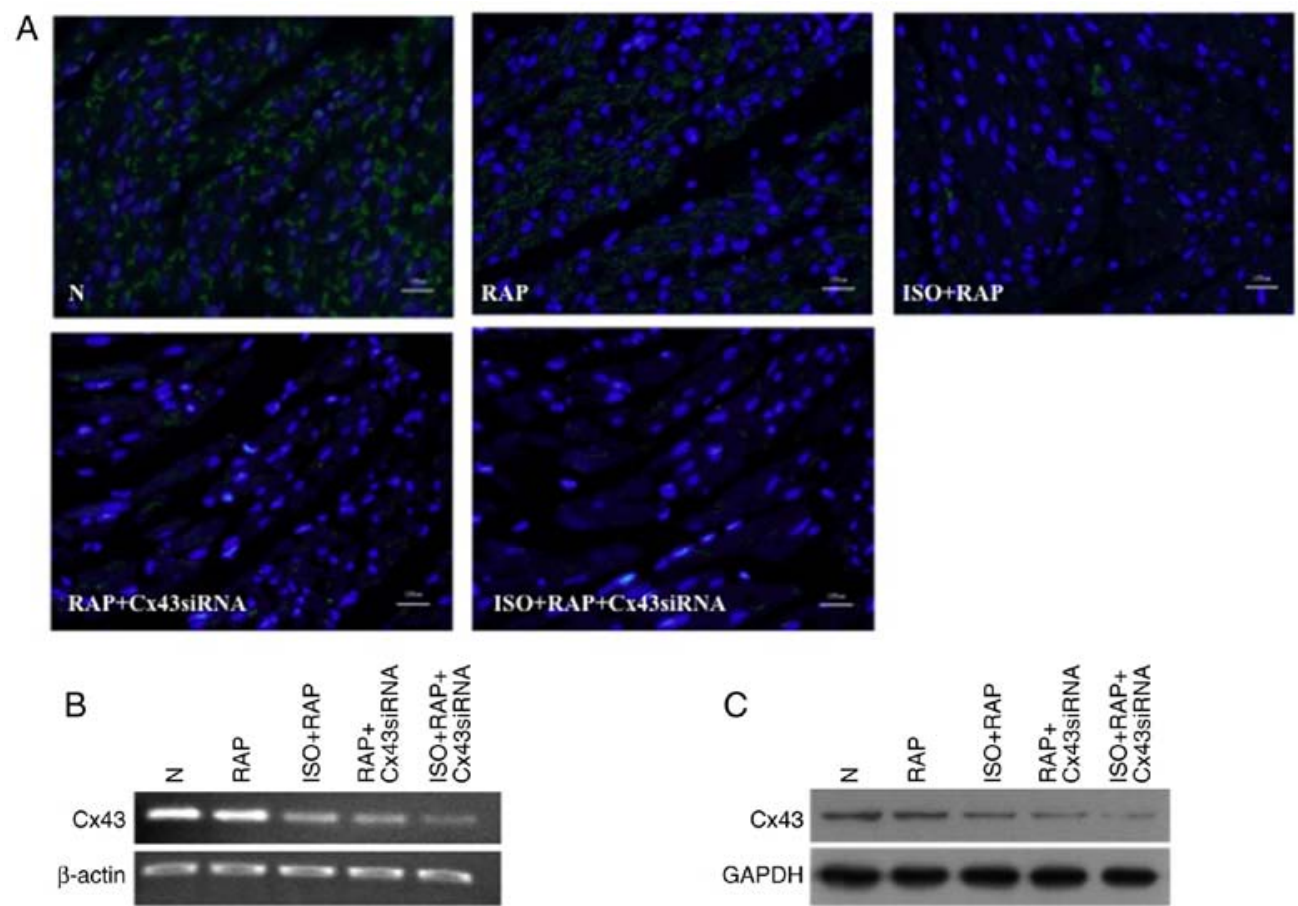

Figure 2. (A) The expression of $\mathrm{Cx} 43$ in the myocardium was assessed using immunohistochemistry. Cx43 (B) mRNA and (C) protein was assessed by reverse transcription-quantitative polymerase chain reaction and western blotting, respectively. Scale bar=50 $\mu \mathrm{m}$. Cx43, connexin 43; N, normal; RAP, rapid atrial pacing; ISO, isoproterenol; siRNA, small interfering RNA.
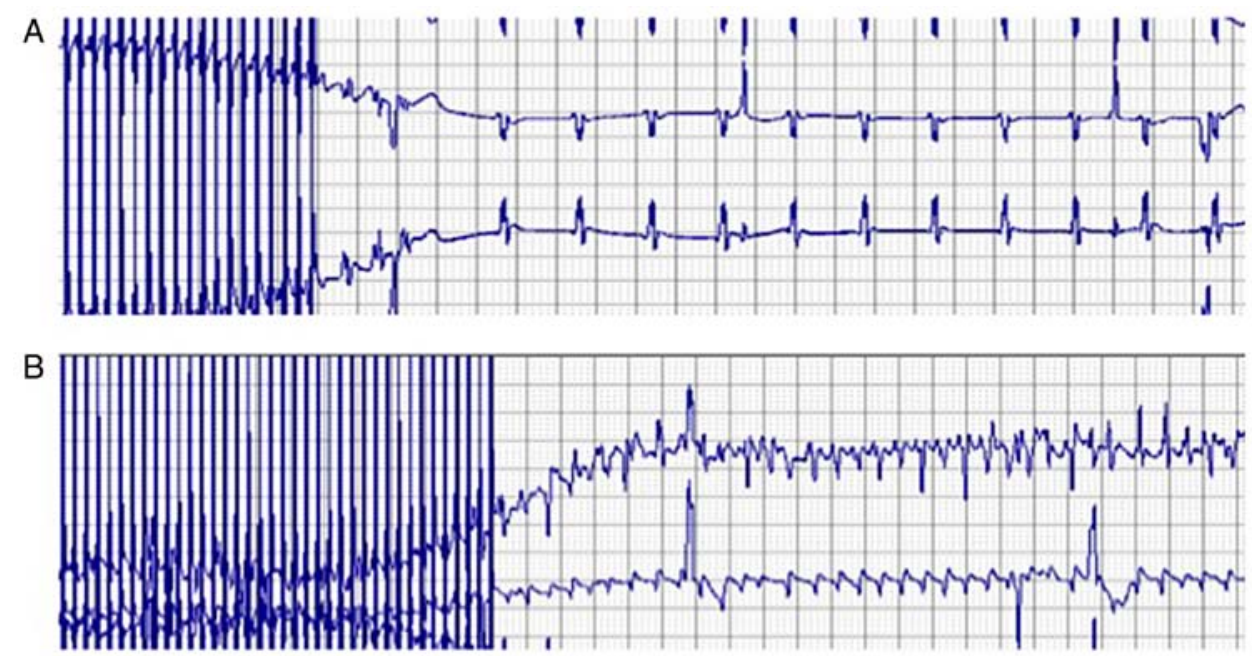

Figure 3. Induction rates of atrial fibrillation. (A) Transient electrical disorder was observed in the RAP group. (B) Atrial fibrillation was induced in the ISO + RAP, RAP + Cx43 siRNA and ISO + RAP + Cx43 siRNA groups. A representative image from the ISO + RAP group is shown. Cx43, connexin 43; N, normal; RAP, rapid atrial pacing; ISO, isoproterenol; siRNA, small interfering RNA. 
Table I. Cx43 mRNA in each group $(n=5)$.

\begin{tabular}{ll}
\hline Group & Cx43 mRNA \\
\hline $\mathrm{N}$ & $1.01 \pm 0.01$ \\
$\mathrm{RAP}$ & $0.63 \pm 0.05^{\mathrm{a}}$ \\
ISO + RAP & $0.36 \pm 0.04^{\mathrm{a}, \mathrm{b}}$ \\
RAP + CX43 siRNA & $0.27 \pm 0.03^{\mathrm{a}, \mathrm{b}, \mathrm{c}}$ \\
ISO + RAP + CX43 siRNA & $0.17 \pm 0.01^{\mathrm{a}, \mathrm{c}, \mathrm{d}}$
\end{tabular}

aa $<0.05$ vs. $\mathrm{N},{ }^{\mathrm{b}} \mathrm{P}<0.05$ vs. RAP, ${ }^{\mathrm{c}} \mathrm{P}<0.05$ vs. ISO $+\mathrm{RAP}$ and ${ }^{\mathrm{d}} \mathrm{P}<0.05$ vs. RAP + Cx43 siRNA. Cx43, connexin 43; N, normal; RAP, rapid atrial pacing; ISO, isoproterenol; siRNA, small interfering RNA.

Table II. AERP in each group $(n=5)$.

\begin{tabular}{lc}
\hline Group & AERP (msec) \\
\hline $\mathrm{N}$ & $166 \pm 5.1$ \\
$\mathrm{RAP}$ & $160 \pm 3.2$ \\
ISO + RAP & $148 \pm 3.7^{\mathrm{a}}$ \\
RAP + Cx43 siRNA & $156 \pm 2.4$ \\
ISO + RAP + Cx43 siRNA & $144 \pm 2.2^{\mathrm{a}}$ \\
\hline
\end{tabular}

${ }^{\text {a }} \mathrm{P}<0.05$ vs. N. AERP, atrial effective refractory period; N, normal; RAP, rapid atrial pacing; ISO, isoproterenol; $\mathrm{Cx} 43$, connexin 43; siRNA, small interfering RNA.

$(\mathrm{P}<0.05$; Table I and Fig. 2B). It was also significantly reduced in the ISO + RAP and RAP + Cx43 siRNA groups compared with the RAP group ( $\mathrm{P}<0.05$, Table I; Fig. 2B). Compared with the ISO + RAP group, the level of Cx43 mRNA in the RAP + Cx43 siRNA and ISO + RAP + Cx43 siRNA groups was downregulated $(\mathrm{P}<0.05$, Table I; Fig. $2 \mathrm{~B})$. Compared with the $\mathrm{RAP}+$ Cx43 siRNA group, the level of Cx43 in the ISO + RAP + Cx43 siRNA group was also decreased $(\mathrm{P}<0.05$, Table I; Fig. 2B). At the protein level, total $\mathrm{Cx} 43$ was gradually decreased in all experimental groups compared with the $\mathrm{N}$ group (Fig. 2C).

Comparison of AERP among groups. The AERP level was not significantly altered in the RAP and RAP + Cx43 siRNA group; however, it was significantly reduced in the ISO + RAP and ISO + RAP + Cx43 siRNA groups $(\mathrm{P}<0.05$; Table II $)$, compared with the $\mathrm{N}$ group respectively. Compared with the RAP group, the AERP was not significantly affected in the RAP + Cx43 siRNA group. Compared with the ISO + RAP group, no significant difference in AERP was observed in the ISO + RAP + Cx43 siRNA group, suggesting that Cx43 knockdown has a minimal effect.

Induction rates of AF in each group. AF could not be induced in the N and RAP groups; only transient atrial electrical disorder was observed in the RAP group (Fig. 3A). However, AF was clearly induced in the ISO + RAP, RAP + Cx43 siRNA $(\mathrm{P}<0.05$; Table III) and ISO + RAP + Cx43 siRNA $(\mathrm{P}<0.01$; Table III $)$ groups compared with the $\mathrm{N}$ group (Fig. $3 \mathrm{~B}$ ). Compared with the RAP + Cx43 siRNA group, the induction rates of AF in the ISO
Table III. Induction rates of atrial fibrillation $(n=5)$.

\begin{tabular}{lc}
\hline Group & Induction rate (\%) \\
\hline $\mathrm{N}$ & $0 \pm 0$ \\
$\mathrm{RAP}$ & $0 \pm 0$ \\
$\mathrm{ISO}+\mathrm{RAP}$ & $8.6 \pm 0.8^{\mathrm{a}, \mathrm{c}}$ \\
$\mathrm{RAP}+\mathrm{CX} 43$ siRNA & $3.3 \pm 1.1^{\mathrm{a}}$ \\
ISO + RAP + CX43 siRNA & $11.9 \pm 1.7^{\mathrm{b}, \mathrm{c}, \mathrm{d}}$
\end{tabular}

${ }^{\mathrm{a}} \mathrm{P}<0.05$ and ${ }^{\mathrm{b}} \mathrm{P}<0.01$ vs. $\mathrm{N},{ }^{\mathrm{c}} \mathrm{P}<0.01$ vs. $\mathrm{RAP}+\mathrm{Cx} 43$ siRNA and ${ }^{\mathrm{d}} \mathrm{P}<0.05$ vs. ISO + RAP. N, normal; RAP, rapid atrial pacing; ISO, isoproterenol; Cx43, connexin 43; siRNA, small interfering RNA.

Table IV. ROS production in each group $(n=5)$.

\begin{tabular}{lc}
\hline Group & $\begin{array}{c}\text { ROS } \\
\text { (fluorescence intensity) }\end{array}$ \\
\hline $\mathrm{N}$ & $108.2 \pm 2.4$ \\
RAP & $288.1 \pm 2.4^{\mathrm{a}}$ \\
ISO + RAP & $337.4 \pm 2.6^{\mathrm{a}, \mathrm{b}}$ \\
RAP + CX43 siRNA & $351.6 \pm 2.0^{\mathrm{a}, \mathrm{b}, \mathrm{c}}$ \\
ISO + RAP + CX43 siRNA & $355.9 \pm 3.1^{\mathrm{a}, \mathrm{b}, \mathrm{c}}$ \\
\hline
\end{tabular}

${ }^{\mathrm{a}} \mathrm{P}<0.01$ vs. $\mathrm{N},{ }^{\mathrm{b}} \mathrm{P}<0.01$ vs. RAP and ${ }^{\mathrm{c}} \mathrm{P}<0.05$ vs. ISO + RAP. ROS, reactive oxygen species; N, normal; RAP, rapid atrial pacing; ISO, isoproterenol; Cx43, connexin 43; siRNA, small interfering RNA.

+ RAP and ISO + RAP + Cx43 siRNA groups were significantly increased $(\mathrm{P}<0.01$; Table III). Compared with the ISO + RAP group, the induction rate of AF in the ISO + RAP + Cx43 siRNA group was also significantly increased $(<\mathrm{P}<0.05$; Table III).

Immunohistochemical analysis for NGF and TH in each group. Immunohistochemical staining was performed to examine the expression of NGF and TH in each group. Compared with the $\mathrm{N}$ group, NGF expression was markedly increased in the other groups (Fig. 4A). Compared with the RAP and RAP $+\mathrm{Cx} 43$ siRNA groups, the levels of NGF in the ISO + RAP and ISO + RAP + Cx43 siRNA groups were increased (Fig. 4A). However no difference in NGF was observed between the ISO $+\mathrm{RAP}$ and ISO + RAP + Cx43 siRNA groups, or the RAP and RAP + Cx43 siRNA groups (Fig. 4A). This suggests that Cx43 does not regulate the expression of NGF. TH was specifically stained in the nuclei. Compared with the $\mathrm{N}$ group, a markedly higher positive rate of TH staining was observed in the other groups. Furthermore, more positive staining was observed in the ISO + RAP group compared with the RAP group. However, no obvious difference in staining was observed between the ISO + RAP and ISO + RAP + Cx43 siRNA groups, or the RAP and RAP + Cx43 siRNA groups (Fig. 4B), which suggests that $\mathrm{Cx} 43$ does not regulate the expression of TH either.

Mitochondrial ROS production. Compared with the N group, ROS production was significantly increased in all other groups $(\mathrm{P}<0.01$; Table IV). Compared with the RAP group, 

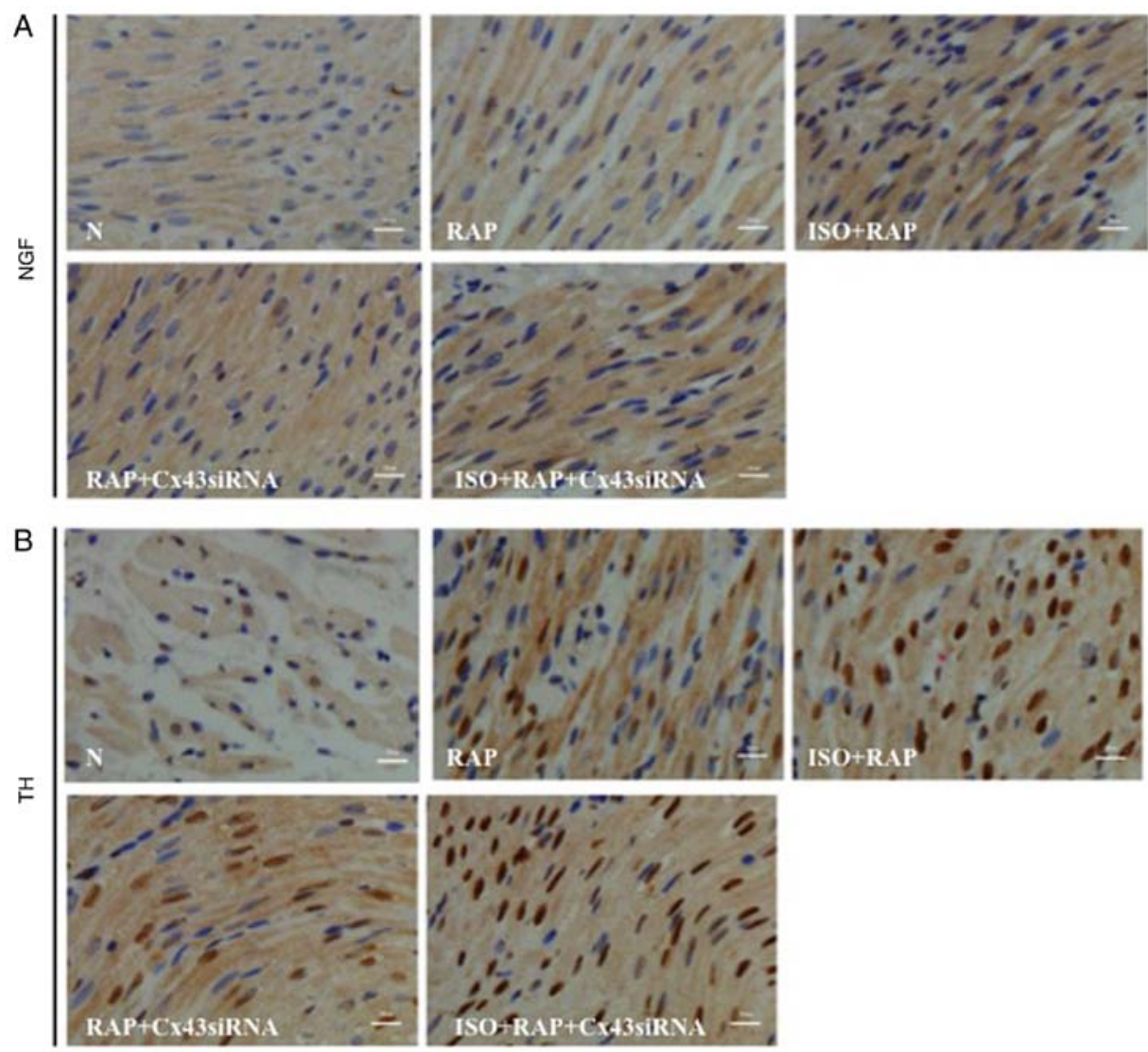

Figure 4. Immunohistochemical analysis of (A) NGF and (B) TH in each group. Scale bar=50 $\mu \mathrm{m}$. NGF, nerve growth factor; TH, tyrosine hydroxylase; $\mathrm{N}$, normal; RAP, rapid atrial pacing; ISO, isoproterenol; Cx43, connexin 43; siRNA, small interfering RNA.
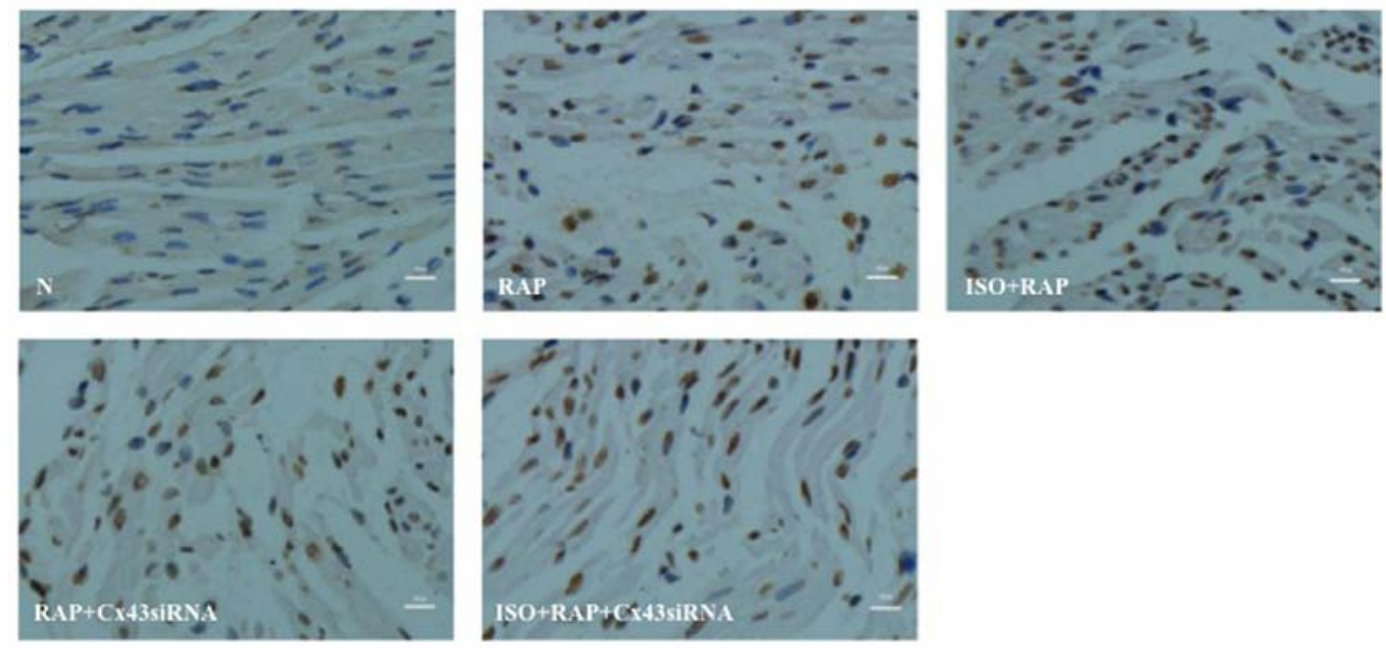

Figure 5. TUNEL staining was performed to assess apoptotic myocytes in each group. Scale bar=50 $\mu \mathrm{m}$. N, normal; RAP, rapid atrial pacing; ISO, isoproterenol; Cx43, connexin 43; siRNA, small interfering RNA.

ROS production in the ISO + RAP, RAP + Cx43 siRNA and ISO + RAP + Cx43 siRNA groups was significantly increased $(\mathrm{P}<0.01$; Table IV), which demonstrated that ISO and $\mathrm{Cx} 43$ knockdown affected the ROS production. Compared with the ISO + RAP group, ROS production was significantly increased in the RAP + Cx43 siRNA and ISO + RAP + Cx43 siRNA groups $(\mathrm{P}<0.05$; Table IV), which suggests that $\mathrm{Cx} 43$ knockdown had a greater effect than ISO on ROS production. However, no significant difference was observed between the
$\mathrm{RAP}+\mathrm{Cx} 43$ siRNA and ISO + RAP + Cx43 siRNA groups (Table IV), suggesting that ISO failed to affect ROS production when $\mathrm{Cx} 43$ was depleted.

Apoptotic myocardial cells. The nuclei of apoptotic myocardial cells were stained dark brown and non-apoptotic cells were stained blue (Fig. 5). The AI in each group was significantly increased compared with the $\mathrm{N}$ group $(\mathrm{P}<0.01$; Table $\mathrm{V})$ 

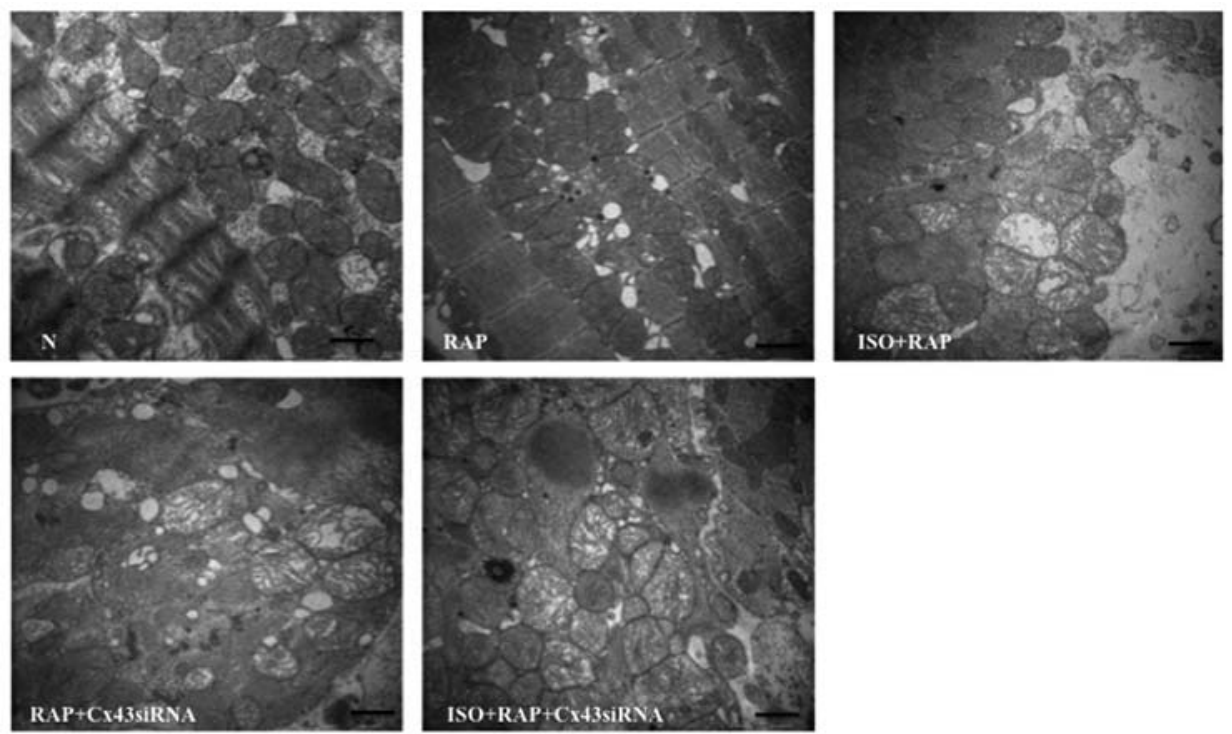

Figure 6. Mitochondrial damage in each group was examined using transmission electron microscopy. Scale bar=1 $\mu \mathrm{m}$. N, normal; RAP, rapid atrial pacing; ISO, isoproterenol; Cx43, connexin 43; siRNA, small interfering RNA.

Table V. Apoptotic index in each group.

\begin{tabular}{lc}
\hline Group & Apoptotic index (\%) \\
\hline $\mathrm{N}$ & $8.3 \pm 0.7$ \\
RAP & $35.2 \pm 1.2^{\mathrm{a}}$ \\
ISO + RAP & $54.2 \pm 1.1^{\mathrm{a}, \mathrm{b}}$ \\
RAP + CX43 siRNA & $60.5 \pm 0.6^{\mathrm{a}, \mathrm{c}}$ \\
ISO + RAP + CX43 siRNA & $69.3 \pm 0.6^{\mathrm{a}, \mathrm{d}}$ \\
\hline
\end{tabular}

${ }^{\mathrm{a}} \mathrm{P}<0.01$ vs. $\mathrm{N},{ }^{b} \mathrm{P}<0.01$ vs. $\mathrm{RAP},{ }^{\mathrm{c}} \mathrm{P}<0.01$ vs. ISO + RAP and ${ }^{\mathrm{d}} \mathrm{P}<0.01$ vs. RAP + Cx43 siRNA. N, normal; RAP, rapid atrial pacing; ISO, isoproterenol; Cx43, connexin 43; siRNA, small interfering RNA.

and it was increased in the ISO + RAP + Cx43 siRNA group compared with the RAP group to $(\mathrm{P}<0.01$; Table $\mathrm{V})$.

Mitochondrial morphology. TEM was used to examine the mitochondrial morphology in each group (Fig. 6). In the $\mathrm{N}$ group, the mitochondria were not swollen, with regular and dense cristae. In the RAP group, the mitochondria were slightly swollen and the matrix was almost unaffected, with irregular and mildly disrupted cristae. However, in the ISO + RAP, $\mathrm{RAP}+\mathrm{Cx} 43$ siRNA and ISO + RAP + Cx43 siRNA groups, the mitochondria were clearly swollen, with transparent matrix and disordered and disrupted cristae (Fig. 6).

\section{Discussion}

At present, the exact mechanism underlying the initiation, maintenance and recurrence of atrial fibrillation is unclear. Although previous studies have demonstrated that remodeling and regeneration of the sympathetic nervous system are associated with the occurrence and maintenance of atrial fibrillation (23-25), there is a lack of detailed information. In order to better understand the underlying mechanism. An ISO perfusion was used in the present study to mimic sympathetic excitation in the isolated perfused heart model, in which the impact of neurohumoral regulations could be removed. It has previously been demonstrated that short burst, high-frequency stimulation does not significantly affect AERP (26). The results of the present study suggest that the sympathetic nervous system may be responsible for atrial electrical remodeling, increasing the likelihood of atrial fibrillation. It was observed that ISO perfusion combined with RAP significantly shortened the AERP and increased the induction rate of AF compared with RAP alone, which did not significantly alter these parameters. It was also demonstrated that ISO perfusion with RAP increased the expression of NGF and TH more compared with RAP, although RAP alone also increased their expressions compared with the normal group. This indicates that sympathetic activation may have positive feedback on its own activity via synthesizing more neurotransmitters, as TH is a rate-limiting enzyme in this reaction.

Cellular abnormalities in atrial cardiomyocytes mediate atrial fibrillation induced by sympathetic activation to some extent (27); based on this, gap junctions were the focus of the present study. Gap junctions are a type of specialized linkage structure in the cell membrane between two adjacent cardiomyocytes (28). Gap junctions are composed of two channels, each of which is formed by six circularly arranged connexins that are essential for metabolic and electrical coupling between cardiomyocytes (29). The redistribution and functional change of channels in gap junctions affects the transmission velocity and anisotropic conductive properties, further inducing arrhythmic circuits. Decreased numbers of gap junctions in end-to-end connections between atrial cardiomyocytes results in reduced cellular coupling, which further changes the conductivity of cardiomyocytes and slows down transmission velocity (30).

As one of the major connexins expressed in atria, $\mathrm{Cx} 43$ serves an important role in maintaining normal rhythm, communication and transmission of electrical signals in atrial cardiomyocytes (31). In the present study, the role of $\mathrm{Cx} 43$ in 
atrial fibrillation induced by sympathetic activation under ISO and RAP conditions was explored The results of the present study demonstrate that the levels of $\mathrm{Cx} 43$ protein and transcript were significantly reduced compared with the normal or RAP alone groups. Immunofluorescent staining revealed reduced expression and punctate distribution of $\mathrm{Cx} 43$ in the cytoplasm with a loss of end-to-end distribution in the ISO + RAP group, whereas RAP alone induced lateralization of $\mathrm{Cx} 43$ with a decrease in end-to-end distribution. Oxidative damage was observed in the ISO + RAP group as evidenced by a significant increase in ROS production and the apoptotic index. Electron microscopy revealed that mitochondria were swollen and cristae were fragmented and dissolved. These results were consistent with reports that ISO, a synthetic and non-selective $\beta$-adrenergic agonist, increases the production of ROS and promotes cell apoptosis (32-34). Lenaerts et al reported that oxidative stress is positively correlated with the occurrence of atrial fibrillation (35). Although it is not clear how oxidative stress initiates and maintains atrial fibrillation, one possible mechanism is associated with $\mathrm{Cx} 43$ degradation in response to calcium overload in the cytoplasm resulting from calcium overflow from sarcoplasmic reticula caused by oxidative stress, which subsequently leads to arrhythmia (36).

The results of $\mathrm{Cx} 43$ silencing experiments also indicated that $\mathrm{Cx} 43$ serves a protective role, maintaining normal signal transduction between cardiomyocytes and reducing susceptibility to atrial fibrillation in response to oxidative stress induced by sympathetic activation. When $\mathrm{Cx} 43$ was partially silenced, it was observed that RAP induced atrial fibrillation. For ISO + RAP treatment, the induction rate of atrial fibrillation was significantly higher in the Cx43 silencing group. Furthermore, $\mathrm{Cx} 43$ silencing in the RAP alone or ISO + RAP group resulted in a higher production of ROS by mitochondria, increased apoptotic index and striking changes to the mitochondria compared with their respective control groups. However, no obvious changes in the amount and distribution of NGF and TH were observed in the Cx43 silencing group. These results suggest that $\mathrm{Cx} 43$ silencing led to greater mitochondria damage from oxidative stress induced by ISO profusion and/or RAP. Furthermore, these results suggest a link between $\mathrm{Cx} 43$ and oxidative stress. The authors therefore hypothesize that the sympathetic nervous system may initiate and maintain atrial fibrillation via activating oxidative stress and thus affecting the expression and distribution of $\mathrm{Cx} 43$.

One limitation of the present study is that only total $\mathrm{Cx} 43$ expression was assessed. However, it is known that $\mathrm{Cx} 43$ phosphorylation is important for Cx43 functionality (37), which should be investigated in future studies. Additionally, although an ISO perfusion model was established to mimic sympathetic excitation in the isolated perfused heart model while eliminating the impact of neurohumoral regulations in vivo, the use of this model is limited as it us unable to provide the same conditions as sympathetic activation-induced atrial fibrillation in vivo.

\section{Acknowledgements}

The authors would like to thank Professor Yongxiang Zhao from Guangxi Medical University for their technical support.

\section{Funding}

The present study was supported by the Natural Science Foundation of China (grant nos. 81260039, 81560061 and 81760061), Natural Science Foundation of Guangxi Province (grant nos. S201303-06 and 2013GXNSFAA278005) and the Senior Medical Personnel Training in Guangxi '139' Plan Funding.

\section{Availability of data and materials}

The datasets used during the current study are available from the corresponding author upon request.

\section{Authors' contributions}

$\mathrm{BL}, \mathrm{YY}$ and $\mathrm{YH}$ designed the study and wrote the manuscript. ZZe, ZZh, HaiL analyzed the data. HaoL, JL, WH and JW interpreted the data and revised the language of the manuscript. YH conceived the study. All authors read and approved the final manuscript.

\section{Ethics approval and consent to participate}

All animal experiments were approved by the Ethics Committee of the First Affiliated Hospital of Guangxi Medical University (Nanning, China).

\section{Consent for publication}

Not applicable.

\section{Competing interests}

The authors declare that they have no competing interests.

\section{References}

1. Lin G, Lu HH, Shen Y, Huang JF, Shi LS and Guo YN: Meta-analysis of the therapeutic effects of various methods for the treatment of chronic atrial fibrillation. Exp Ther Med 6: 489-496, 2013.

2. Pellman J and Sheikh F: Atrial fibrillation: Mechanisms, therapeutics, and future directions. Compr Physiol 5: 649-665, 2015.

3. Yi Z, Zhang HC, Zhang P, Liu G, Lu P, Sun JL, Liu B and Guo JH: The relationship of paroxysmal atrial fibrillation and regional sympathetic innervations in the atria and pulmonary veins: Experiment with dogs. Zhonghua Yi Xue Za Zhi 87: 3433-3435, 2007 (In Chinese).

4. Chen PS, Chen LS, Fishbein MC, Lin SF and Nattel S: Role of the autonomic nervous system in atrial fibrillation: Pathophysiology and therapy. Circ Res 114: 1500-1515, 2014.

5. Leybaert L, Lampe PD, Dhein S, Kwak BR, Ferdinandy P, Beyer EC, Laird DW, Naus CC, Green CR and Schulz R: Connexins in cardiovascular and neurovascular health and disease: Pharmacological implications. Pharmacol Rev 69: 396-478, 2017.

6. Del Ry S, Moscato S, Bianchi F, Morales MA, Dolfi A, Burchielli S, Cabiati M and Mattii L: Altered expression of connexin 43 and related molecular partners in a pig model of left ventricular dysfunction with and without dipyrydamole therapy. Pharmacol Res 95-96: 92-101, 2015.

7. Xiao Y, Cai X, Atkinson A, Logantha SJ, Boyett $M$ and Dobrzynski H: Expression of connexin 43, ion channels and $\mathrm{Ca}^{2+}$-handling proteins in rat pulmonary vein cardiomyocytes. Exp Ther Med 12: 3233-3241, 2016. 
8. Cai J, Jiang WG and Mansel RE: Gap junctional communication and the tyrosine phosphorylation of connexin 43 in interaction between breast cancer and endothelial cells. Int J Mol Med 1: 273-278, 1998

9. Han XJ, He D, Xu LJ, Chen M, Wang YQ, Feng JG, Wei MJ, Hong $\mathrm{T}$ and Jiang LP: Knockdown of connexin 43 attenuates balloon injury-induced vascular restenosis through the inhibition of the proliferation and migration of vascular smooth muscle cells. Int J Mol Med 36: 1361-1368, 2015.

10. Brockmeyer P, Jung K, Perske C, Schliephake H and Hemmerlein B: Membrane connexin 43 acts as an independent prognostic marker in oral squamous cell carcinoma. Int $\mathrm{J}$ Oncol 45: 273-281, 2014

11. Han XJ, Chen M, Hong T, Zhu LY, He D, Feng JG and Jiang LP: Lentivirus-mediated RNAi knockdown of the gap junction protein, $\mathrm{Cx} 43$, attenuates the development of vascular restenosis following balloon injury. Int J Mol Med 35: 885-892, 2015.

12. Brockmeyer P, Hemmerlein B, Jung K, Fialka F, Brodmann T, Gruber RM, Schliephake H and Kramer FJ: Connexin subtype expression during oral carcinogenesis: A pilot study in patients with oral squamous cell carcinoma. Mol Clin Oncol 4: 298-302, 2016.

13. Wang Y, Wu Z, Liu X and Fu Q: Gastrodin ameliorates Parkinsons disease by downregulating connexin 43. Mol Med Rep 8: 585-590, 2013.

14. Yi S, Chen Y, Wen L, Yang L and Cui G: Expression of connexin 32 and connexin 43 in acute myeloid leukemia and their roles in proliferation. Oncol Lett 4: 1003-1007, 2012.

15. Sun Y, Zhao X, Yao Y, Qi X, Yuan Y and Hu Y: Connexin 43 interacts with Bax to regulate apoptosis of pancreatic cancer through a gap junction-independent pathway. Int J Oncol 41: 941-948, 2012

16. Fukushima $M$, Hattori $Y$, Yoshizawa $T$ and Maitani $Y$ : Combination of non-viral connexin 43 gene therapy and docetaxel inhibits the growth of human prostate cancer in mice. Int J Oncol 30: 225-231, 2007.

17. Yan Y, Huang J, Ding F, Mei J, Zhu J, Liu H and Sun K: Aquaporin 1 plays an important role in myocardial edema caused by cardiopulmonary bypass surgery in goat. Int J Mol Med 31: 637-643, 2013.

18. Boengler K and Schulz R: Connexin 43 and mitochondria in cardiovascular health and disease. Adv Exp Med Biol 982: 227-246, 2017

19. Sovari AA, Rutledge CA, Jeong EM, Dolmatova E, Arasu D, Liu H, Vahdani N, Gu L, Zandieh S, Xiao L, et al: Mitochondria oxidative stress, connexin43 remodeling, and sudden arrhythmic death. Circ Arrhythm Electrophysiol 6: 623-631, 2013.

20. Duffy HS and Wit AL: Is there a role for remodeled connexins in AF? No simple answers. J Mol Cell Cardiol 44: 4-13, 2008.

21. Shu C, Huang W, Zeng Z, He Y, Luo B, Liu H, Li J and Xu J: Connexin 43 is involved in the sympathetic atrial fibrillation in canine and canine atrial myocytes. Anatol J Cardiol 18: 3-9, 2017.

22. Livak KJ and Schmittgen TD: Analysis of relative gene expression data using real-time quantitative PCR and the 2(-delta delta C(T)) method. Methods 25: 402-408, 2001.

23. Volders PG: Novel insights into the role of the sympathetic nervous system in cardiac arrhythmogenesis. Heart Rhythm 7: 1900-1906, 2010.
24. Yu L, Li X, Huang B, Zhou X, Wang M, Zhou L, Meng G, Wang Y, Wang Z, Deng J and Jiang H: Atrial fibrillation in acute obstructive sleep apnea: Autonomic nervous mechanism and modulation. J Am Heart Assoc 6, 2017.

25. Li Y, Lu Z, Tang Q, Jiang H, Huang C, He B, Hu X, Huang J, $\mathrm{Zhu} \mathrm{X}$ and Wang $\mathrm{H}$ : The increase in sympathetic nerve density in the atrium facilitates atrial fibrillation in patients with rheumatic heart disease. Int J Cardiol 165: 174-178, 2013.

26. Zhang L, Po SS, Wang H, Scherlag BJ, Li H, Sun J, Lu Y, Ma Y and Hou Y: Autonomic remodeling: How atrial fibrillation begets atrial fibrillation in the first 24 hours. J Cardiovasc Pharmacol 66: 307-315, 2015.

27. Saygili E, Rana OR, Gunzel C, Günzel C, Rackauskas G, Saygili E, Noor-Ebad F, Gemein C, Zink MD, Schwinger RH, Mischke K, et al: Rate and irregularity of electrical activation during atrial fibrillation affect myocardial NGF expression via different signalling routes. Cell Signal 24: 99-105, 2012.

28. Ribeiro-Rodrigues TM, Martins-Marques T, Morel S, Kwak BR and Girão H: Role of connexin 43 in different forms of intercellular communication-gap junctions, extracellular vesicles and tunnelling nanotubes. J Cell Sci 130: 3619-3630, 2017.

29. Palatinus JA, Rhett JM and Gourdie RG: The connexin43 carboxyl terminus and cardiac gap junction organization. Biochim Biophys Acta 1818: 1831-1843, 2012.

30. Lee HC: Electrical remodeling in human atrial fibrillation. Chin Med J 126: 2380-2383, 2013.

31. Nagibin V, Egan Benova T, Viczenczova C, Szeiffova Bacova B, Dovinova I, Barancik $M$ and Tribulova N: Ageing related down-regulation of myocardial connexin-43 and up-regulation of MMP-2 may predict propensity to atrial fibrillation in experimental animals. Physiol Res (65 Suppl 1): S91-S100, 2016.

32. Davel AP, Brum PC and Rossoni LV: Isoproterenol induces vascular oxidative stress and endothelial dysfunction via a Gialpha-coupled $\beta 2$-adrenoceptor signaling pathway. PloS One 9: e91877, 2014.

33. Kumar M, Kasala ER, Bodduluru LN, Dahiya V and Lahkar M: Baicalein protects isoproterenol induced myocardial ischemic injury in male Wistar rats by mitigating oxidative stress and inflammation. Inflamm Res 65: 613-622, 2016.

34. Yin Q, Lu H, Bai Y, Tian A, Yang Q, Wu J, Yang C, Fan TP, Zhang Y, Zheng X, et al: A metabolite of Danshen formulae attenuates cardiac fibrosis induced by isoprenaline, via a NOX2/ROS/p38 pathway. Br J Pharmacol 172: 5573-5585, 2015.

35. Lenaerts I, Driesen RB, Hermida N, Holemans P, Heidbüchel H, Janssens S, Balligand JL, Sipido KR and Willems R: Role of nitric oxide and oxidative stress in a sheep model of persistent atrial fibrillation. Europace 15: 754-760, 2013.

36. Zhou P, Zhang SM, Wang QL, Wu Q, Chen M and Pei JM: Anti-arrhythmic effect of verapamil is accompanied by preservation of cx43 protein in rat heart. PloS One 8: e71567, 2013.

37. Adam O, Lavall D, Theobald K, Hohl M, Grube M, Ameling S, Sussman MA, Rosenkranz S, Kroemer HK, Schäfers HJ, et al: Racl-induced connective tissue growth factor regulates connexin 43 and $\mathrm{N}$-cadherin expression in atrial fibrillation. J Am Coll Cardiol 55: 469-480, 2010. 